Cinémas

Revue d'études cinématographiques

Journal of Film Studies

\title{
Américanité ou américanisation : l'exemple de la coproduction au Québec
}

\section{Chantal Nadeau}

Volume 1, numéro 1-2, automne 1990

Américanité et cinéma

URI : https://id.erudit.org/iderudit/1000991ar

DOI : https://doi.org/10.7202/1000991ar

Aller au sommaire du numéro

Éditeur(s)

Cinémas

ISSN

1181-6945 (imprimé)

1705-6500 (numérique)

Découvrir la revue

Citer cet article

Nadeau, C. (1990). Américanité ou américanisation : l'exemple de la coproduction au Québec. Cinémas, 1(1-2), 60-71.

https://doi.org/10.7202/1000991ar
Résumé de l'article

La coproduction au Québec est considérée non pas comme le seul fait d'une américanisation des pratiques cinématographiques, mais comme participant également d'une certaine expression de l'américanité. Le présent texte questionne l'espace de plus en plus « hybride » dans lequel semble se mouvoir le cinéma québécois contemporain. Une analyse de quelques coproductions récentes produites au Québec vient illustrer ce va-et-vient entre référents jugés " autres " et reconnaissance "spécifique ", de façon à montrer le rapport entre coproduction et cinéma dit national en regard d'une problématique de l'hybridité culturelle. 


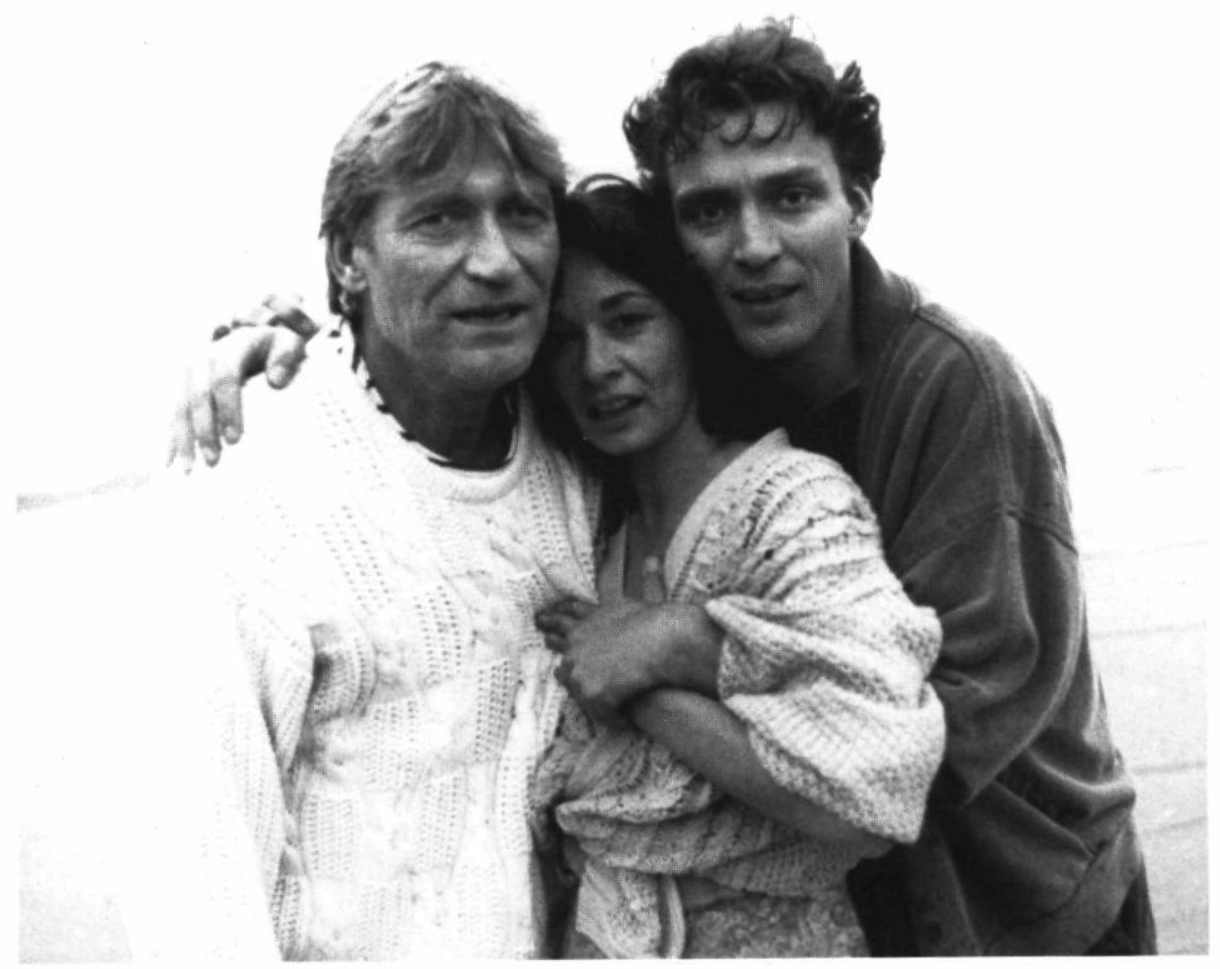

À corps perdu de Léa Pool (1988)

Coll. Cinémathèque québécoise 


\title{
Américanité ou américanisation: l'exemple de la coproduction au Québec
}

\section{Chantal Nadeau}

\begin{abstract}
RÉSUMÉ
La coproduction au Québec est considérée non pas comme le seul fait d'une américanisation des pratiques cinématographiques, mais comme participant également d'une certaine expression de l'américanité. Le présent texte questionne l'espace de plus en plus «hybride» dans lequel semble se mouvoir le cinéma québécois contemporain. Une analyse de quelques coproductions récentes produites au Québec vient illustrer ce va-et-vient entre référents jugés «autres» et reconnaissance "spécifique», de façon à montrer le rapport entre coproduction et cinéma dit national en regard d'une problématique de l'hybridité culturelle.
\end{abstract}

\begin{abstract}
In Quebec, co-production is considered both as simply one aspect of the Americanization of cinematic practices and also as a means to express of a certain "Americanness". This text examines the increasingly "hybrid" space that contemporary Quebec cinema seems to inhabit. An analysis of a number of recent co-productions made in Quebec illustrates the interplay between referents seen as "other" and as "specific" in order to demonstrate the relationship between co-production and "national" cinema in terms of cultural hybridity.
\end{abstract}

Comment voir le cinéma québécois à travers le phénomène de la coproduction'1? Paria d'une cinématographie, la coproduction au Québec est-elle le jeu de l'américanisation du cinéma, c'est-à-dire d'une production cinématographique qui s'inscrit à l'heure de la 
«transnationalité» de la culture - voire d'une production culturelle industrialisée de plus en plus standardisée? Ou encore, ne renvoie-t-elle pas à un «espace public» où se percutent et se répercutent les aléas de l'altérité, de ces regards autres tissés à même la reconnaissance de soi?

Phénomène hybride certes que celui de la coproduction, il s'agira de poser cette dernière problématique dans la perspective plus globale, sinon plus «ouverte» des croisements de cultures soit, ici, ce qui sera désigné sous l'appellation conceptuelle d'hybridité culturelle - et de voir en quoi, à la jonction de la coproduction et d'une production cinématographique plus spécifique (nationale?), s'interpellent les pièges et les subterfuges de l'américanisation et de l'américanité...

Quelques exemples de coproductions récentes au Québec viendront étayer le propos: de l'adaptation cinématographique Les Portes tournantes (Francis Mankiewicz, 1988) ${ }^{2}$ au film Les Tisserands du pouvoir (Claude Fournier, 1988) en passant par $\dot{A}$ corps perdu (Léa Pool, 1988) ${ }^{3}$.

\section{L'interaction culturelle ou l'esthétique de l'autre.}

L'histoire se passe quelque part à Montréal..., du moins on le présume. Mais on aurait pu tout aussi bien être «ailleurs» et pourquoi pas dans un ailleurs évanescent. Atelier de peintre dans le plus pur archétype fantasmagorique de ce que devrait être un atelier de peintre: grand espace, grand bonhomme - l'artiste... grands formats bariolés (la mode n'est-elle pas au gigantisme et au more-more 4 ?), le tout se profilant sur une toile de fond aux contours vaguement vert-de-gris. Un visage hirsute - réincarnation mythique d'un Rodin québécois converti aux vertus de la couleur? - jaillit d'un quelconque chef-d'œuvre, représentation torturée du nec plus ultra de l'âme artistique. Le peintre en question, incarné à l'écran par Gabriel Arcand, est québécois, mais baigne dans la sauce onctueuse, doux héritage infantile, de la culture parisienne. Devoir oblige, la coproduction a la dent longue et le cliché frémissant.

En effet, non seulement la politique coproductrice en matière de cinéma ne saurait se satisfaire de déviances psycho-caractérielles, mais requiert ni plus ni moins la présence du joli «minois» de l'autre culture - auréolée ici sous la houppette blondinette de l'apatride Miou-Miou - , histoire de rappeler que l'autre culture, c'est aussi la culture de l'un, surtout que l'un a à voir avec les tribulations génitrices et historicistes de l'autre. 
étranger seulement aux yeux des autochtones, ce n'est pas là une qualité intrinsèque; dire de quelqu'un qu'il est étranger, c'est évidemment en dire très peu» (p. 9).

Et c'est en effet très peu dire et à la fois trop dire (l'insuffisance du dit ouvrant à la saturation du non-dit) que de se plier à ce genre descriptif consumé que j'ai emprunté pour situer le contexte de la coproduction Les Portes tournantes. Toutefois cet aparté a le mérite, je crois, de montrer jusqu'à quel point les croisements de cultures dans un espace tel que celui de l'écran cinématographique par exemple, peuvent sur le plan de la réception - et ce au-delà du délire paroxystique auquel les coproductions semblent parfois prêter lieu - suggérer l'éclectisme. Question d'identité argueront certains; questions de perception soutiendront pour leur part d'autres. Questions d'altérité répondrait Todorov, soit de «la possibilité de comprendre un autre que moi» (p. 5) ${ }^{5}$; ou encore du «comment juger les contacts entre cultures (ou leur absence)?» (p. $16)^{6}$.

En somme, avec la coproduction, c'est comme s'il s'agissait d'établir le passage en douce du couple singulier «soi» et l'«autre» à la question référentielle sur le plan social - sinon universel du «nous» et des «autres»; car les citations (formelles et esthétiques) ne sont plus uniquement d'ordre interne, mais également d'ordre externe, c'est-à-dire en regard des autres cultures. L'hybridité culturelle est dès lors d'autant plus ambiguë, qu'elle ne marque plus uniquement la redevance du rapport exclusif de soi à l'autre, mais également celle du mouvement perpétuel entre «nous et les autres».

Mais qu'en est-il toutefois quand il s'agit de voir le cinéma québécois à travers le phénomène de la coproduction? Non pas qu'il suffise de dire que l'un existe pour que l'autre expire...; au contraire c'est, je crois, dans l'apparente non-rencontre des deux que résiderait l'intérêt d'interroger la valeur altérité dans la coproduction.

En effet, pour peu que l'on s'attarde aux incidences du contexte économique et institutionnel sur la production fictionnelle ces dernières années - et ce non seulement dans le cas du cinéma québécois, mais également dans la majorité des cinématographies nationales s'inscrivant dans l'axe du cinéma narratif-représentatif -, force est de constater que le cinéma tend de plus en plus, sous l'impulsion récente (et tout à fait postmoderne?) d'une pratique de la saturation et de la citation, à développer une esthétique qui intégrerait de nombreuses références implicites (illicites?) aux cinématographies autres.

Ainsi, devant un cinéma déjà lourdement traversé et sanctionné de nombreux emprunts - en outre, via l'élargissement sans cesse 
croissant de son champ référentiel $\left(\right.$ Scarpetta $\left.^{7}\right)$ - il devient des plus complexes, voire aléatoire, de départager ce qui participe ou non d'une culture autre. Et, à cet égard, je pense que cette difficulté de définir, voire de signifier l'appartenance culturelle tient, finalement, à un phénomène de plus en plus patent dans le cinéma actuel: soit celui d'une double référence à l'hybridité.

En effet, pour peu que l'on s'attache à la production du cinéma telle qu'elle apparaît ces dernières années, il est possible d'y remarquer une double allégeance à l'hybridité: une à l'interne qui pose, comme je l'ai déjà souligné, toute la question de la «transversalité» artistique et des métissages esthétiques; l'autre à l'externe qui, parce qu'elle se situe à la frontière d'expressions formelles de même nature cinématographique mais se réclamant de cultures différentes, soulève la problématique de la spécificité et de la différence dans le croisement des cultures.

En reconnaissant l'existence de cette double référence à l'hybridité, il apparaît on ne peut plus clairement qu'il ne suffit plus uniquement d'appartenir au domaine réservé et officiel de la coproduction pour croiser une culture autre. Le cinéma citationnel (Scarpetta, mais par «emprunt» à $\mathrm{Eco}^{8}$ ) semble, au contraire, faire loi: les emprunts n'ont jamais été aussi systématiques, les corrélations artistiques aussi présentes.

Les clins d'oeil racoleurs que s'adressent mutuellement les réalisateurs deviennent légion. Même une ineptie hollywoodienne comme Beettlejuice (1988) se targue de citer Buñuel en reproduisant, voire en déguisant littéralement le cérémonial du repas dans Le Charme discret de la bourgeoisie (1972). Un film d'auteur québécois comme Un zoo, la nuit (Jean-Claude Lauzon, 1987) s'inspire illico du Français Beneix (Diva, 1981) ou de l'Américain Friedkin (Cruising, avec Al Pacino, 1980). Et je ne parle pas ici des allusions implicites aux sempiternels miroirs d'Orson Welles, dans The Lady from Shangaï (1948), dans une panoplie de films dont les plus récentes exhibitions vont de l'indéfectible production hollywoodienne (The Accidental Tourist, 1988), au tout premier long métrage de la réalisatrice hongroise Ildiko Enyedi (Mon XXe siècle, 1989).

De cette esthétique citationnelle émanent donc les effluves de l'hybridité culturelle. Car ce qui triomphe dans ces films, c'est une interaction culturelle fondée sur la reconnaissance de soi par l'autre, mais où prédomine une logique d'accumulation sans fin de «lectures» exponentielles du «nous» sur «les autres». Ce processus agit à un point tel que l'on peut presque y décrypter une généralisation esthétique (entendue au sens formel et critique) qui serait née du subterfuge de la négation du référent - identifié ici comme 
«autre» - par la multiplication des références - qui, elles, s'érigent en toute impunité comme «nôtres».

Ainsi, le référent du référent vient imposer son expression normative. Mais cette "guerre du faux» (Eco) par référence esthétique interposée ne pourrait traduire que la propre inertie du cinéma narratif-représentatif «national» à se penser autrement que dans une recherche débridée du «look» transcendant. Dans cette veine, le cynisme d'un cinéma dit transnational ne serait-il pas justement d'être l'héritier don quichottesque d'une esthétique de la différence? À la quête sibylline de l'un, viendrait se confronter le regard mièvre et méprisant d'un cinéma synthétisant qui resquille tout, à un point tel qu'il se joue de sa propre référence: soit en s'immisçant dans une structure pyramidale où débordements iconoclastes et collusions iconolâtres cogitent à la même enseigne, soit en n'hésitant pas à pervertir son sommet au moyen d'une image aseptisée qui sied si bien au code qui fait loi.

C'est pourquoi la coproduction, en tant que lieu, espace d'interaction entre le «nous et les autres», pose toute l'amplitude sous-jacente à la question de l'américanité et de l'américanisation, au sens où il s'agit d'interroger le contexte par lequel s'institue une définition du cinéma québécois («national»). À cet égard, la coproduction, ne serait-ce que parce qu'elle met à jour les contradictions inhérentes aux croisements interculturels, rejoint en tout point la logique qui anime l'hybridité culturelle: soit de faire de la «transversalité» le fondement d'une interaction entre le sujet et l'objet. Il est à se demander, dans cette optique, s'il ne conviendrait pas de réfléchir sur l'apport d'une sociologie qui reconnaîtrait - pour le dire à la façon dont les féministes l'ont posé... - que le sujet ne pourrait exister en tant que sujet que parce qu'il s'est d'abord et avant tout constitué comme objet.

C'est à ce niveau que la coproduction peut offrir une perspective pour le moins intéressante. En effet, dans le contexte particulier d'une sociologie de l'altérité, voire d'une sociologie des «récepteurs», la coproduction pose fort à propos le paradoxe de l'interne et de l'externe, au sens où le regard posé sur la coproduction ne procède plus uniquement de l'extérieur, mais également de l'intérieur. En d'autres termes, c'est comme s'il s'agissait, par un curieux faux-semblant d'ubiquité, d'avoir la possibilité de se regarder en même temps que l'on se voit.

Et qui plus est, la difficulté de se regarder en même temps que l'on se voit se complexifie quand on se rend compte qu'à l'interne - c'est-à-dire dans le film même - il y a négation/abnégation de la présence multiculturelle; alors que d'un point de vue externe soit du point de vue de celle/celui qui regarde, c'est-à-dire de la spectatrice/du spectateur qui juge... - cette «pluralité» apparaît 
dans toute sa splendeur (ne serait-ce qu'au niveau des codes de «reconnaissance» langagiers...). Dès lors, l'articulation entre le jugement sur les autres et l'interaction avec les autres - constitutive des croisements de cultures - vient en quelque sorte éclairer le paradoxe interne/externe, d'autant plus visible sur le plan d'une réception critique qu'il se veut invisible sur le plan d'une production idéologique.

Est-ce donc dire que sur la seule base d'une «reconnaissance» externe et explicite de l'existence d'une pluralité culturelle, il faille en conclure à l'idée que la coproduction ne participe pas d'une cinématographie nationale, et, du coup, qu'elle s'inscrit dans le giron d'un cinéma standardisant, où la valeur du produit n'a de commune mesure que le syndrome fétichiste de son label d'exportation?

Et c'est là, à mon avis, dans cette transversalité culturelle, que résident les subterfuges de l'américanisation et de l'américanité. En effet, s'il est une chose dont il faudrait peut-être savoir affranchir la coproduction, c'est bien celle d'une lecture exclusive procédant d'une économie politique. Les études de Mattelart et Michalet ${ }^{9}$ ont certes permis d'aborder la coproduction dans une perspective de mondialisation du champ des expressions culturelles; mais au-delà des rapports de forces effectifs entre pays producteurs et pays prestataires, il y va de la transculturalité qui, elle, outrepasse la question d'appartenance nationale.

C'est pourquoi, bien qu'il soit tentant de noyer la notion de coproduction avec l'idée d'un cinéma «support» de l'industrie, obéissant aux impératifs d'une économie de marché orientée sur le modèle hollywoodien, je crois néanmoins qu'il faille distinguer l'économie politique procédant de la mise en œuvre du produit filmique, et ce que représente ce même produit dans le contexte d'une transversalité, d'une hybridité culturelle.

Dans un tel contexte, il s'avère dès lors pertinent d'interroger jusqu'à quel point l'américanisation, parce qu'associée implicitement à un processus idéologique, ne vient pas en quelque sorte «dynamiter» le regard sur la coproduction; évacuant ainsi tout possible convergent avec l'américanité qui, elle, appartient, pour reprendre les termes de Régine Robin, à «ce transverse culturel, [à] l'horizontalité des perspectives culturelles» (p. 9) par opposition à toute «verticalité», à toute hiérarchisation du domaine de la culture...

$\mathrm{Si}$, comme l'ont noté Yves Bédard et Denis Bellemare, «le regard de l'Autre constitue tout à la fois une preuve et une épreuve» (p. 1), il est alors à se demander ce qu'il advient de cet «autre» quand il se situe au coeur d'une interrogation sur le «nous et les autres». En effet, il est de ces curieux moments dans l'évolution d'une culture: à l'heure de l'individualisme clinquant et bien son- 
nant, il est de rigueur de renforcer l'affirmation de soi par le nous, ne serait-ce que pour être mieux «autre», donc différent. À cet égard, quelques coproductions réalisées au cours des dernières années viennent fort à propos illustrer cette ambiguïté, voire ce paradoxe d'une hybridité à l'interne alimentée par une vision particulière de l'altérité.

\section{De quelques exemples sur la coproduction au Québec: entre la fuite et le mercantilisme?}

La première question qui me vient à l'esprit quand je vois une coproduction est la suivante: en quoi justement une coproduction $x$ est-elle différente d'une production $y$ ? Ou, encore: où est la coproduction dans une coproduction? Prenons comme exemple deux types de coproductions qu'il ne nous viendrait nullement à l'idée de comparer: Les Tisserands du pouvoir et $\grave{A}$ corps perdu.

Dans le cas des Tisserands du pouvoir, il apparaît clairement que sur le plan de la représentation culturelle il y a bien cohabitation, sans enchevêtrement, de deux cultures: québécoise et française. En effet, épisodes français et québécois alternent, les accents se tissent au gré de l'espace territorial, bref le «caractériel» typé à l'extrême trouve son paroxysme dans l'exotisme de la culture des États-Unis. La représentativité américaine est reconstituée à même la dérive d'une vision extérieure et francophone de surcroît. Pour reprendre une idée développée par Greimas, l'atemporalité du discours historique peut parfois se valider par la construction de son propre référent ${ }^{10}$. Ainsi, à l'universalisme d'une culture - francophone - s'oppose le relativisme d'un dualisme linguistique anglais/français - avec, en prime, une reconduction du colonialisme européen.

À corps perdu est une coproduction réalisée par une Québécoise d'origine suisse, à partir d'une adaptation du roman d'un écrivain français, jouée par des acteurs québécois, français et suisses-allemands, produit avec des dollars canadiens et des francs suisses. Mais curieusement, sous cette avalanche de dénominations culturelles hétéroclites, persiste une certaine homogénéité, tout au plus une certaine étrangeté familière. Rien à voir donc avec l'hétérogénéité de la production Les Tisserands du pouvoir, au sens où cette dernière se présente comme une stratification de citations culturelles où la conception de l'«autre» n'a de valeur en soi que parce qu'elle correspond à la copie conforme de la présomption du «nous» sur «les autres».

Et pourtant, pourrait-on protester, le film de Pool a quelque chose de transculturel, quelque chose qui fait «autre», quelque chose, bref, qui permet justement au film de traverser les frontières, tout en se ménageant une certaine reconnaissance, ne serait- 
ce que parce que Léa Pool n'a jamais autant signé, que dans $A$ corps perdu, la désignation, la représentation spatiale et territoriale, en l'occurrence ici Montréal.

On peut dès lors se questionner sur cette logique paradoxale qui veut lier, en un même dénominateur commun, coproduction et américanisation. À cet égard, il convient de se demander pourquoi le film de Léa Pool, tout autant d'ailleurs que le dernier film de Denys Arcand, Jésus de Montréal, n'a pratiquement jamais évoqué, en première instance, la notion de coproduction, alors que le film de Fournier, lui, n'y a pas échappé? Et pourquoi, dans la même veine, le film d'Yves Simoneau, Dans le ventre du dragon, pourtant homologué «film québécois», a toute la prétention d'une production hollywoodienne, tout en se contentant d'en être un fac-similé?

Ces exemples peuvent paraître extrêmes, mais je crois néanmoins qu'ils permettent d'interroger, via la notion d'hybridité culturelle, la frontière entre américanisation et américanité. En somme, il apparaît de plus en plus évident que peu importe l'appartenance cinématographique spécifique, c'est l'interprétation, voire le jugement porté sur l'autre à travers le phénomène d'interaction, qui semble vouloir servir de paramètre à une définition de ce que sont l'américanisation et l'américanité, en regard du cinéma québécois par exemple.

En fait, il ne s'agit plus d'opérer le clivage américanité et américanisation à travers la reconduction traditionnelle cinéma national/cinéma international (voire dans le cas présent, celui de la coproduction), mais plutôt d'interroger la définition de cet espace de plus en plus hybride dans lequel semble vouloir s'exprimer le cinéma au Québec, et dont, je crois, participe résolument la problématique de l'altérité. L'américanité, telle qu'elle se révèle dans le cinéma québécois, apparaît comme le haut fait de ces croisements de cultures où se confronte et se conforte, dans un va-et-vient perpétuel, le regard sur et avec les autres.

Au cours de cet essai, il s'agissait moins de proposer une définition conceptuelle de l'américanité ou de l'américanisation, ou encore de l'hybridité culturelle, que d'essayer d'opérer les possibles d'une rencontre à trois. À la lumière de cette trajectoire, il semble désormais possible de parler de la coproduction comme d'une «dimension publique» où la question de l'altérité trouve écho non seulement dans l'espace d'un cinéma d'appartenance unique (soit en regard d'une culture spécifique), mais également dans un espace hybride et parfois stratifié. Les incidences de la coproduction peuvent trouver prise dans un cinéma plus «national», ne serait-ce qu'en interrogeant ce dernier non plus à travers la question de la différence mais à travers la question de l'«autre», voire des «autres»... ces «autres». 
En ce sens, le piège à éviter à tout prix dans le regard porté sur le «nous» et «les autres» serait celui de confondre en un même propos une appréhension procédant de la différence et celle relevant de l'altérité. Car, comme l'exprime Francis Affergan, trop souvent en cherchant à faire une sociologie de l'altérité, on se trouve à reproduire une sociologie de la différence ${ }^{11}$.

C'est pourquoi le regard porté sur le phénomène de la coproduction au Québec, telle qu'elle apparaît et dans la tangente manifeste qu'elle semble vouloir emprunter, se veut aussi une réflexion critique sur la définition de ce qui pourrait être le cinéma québécois dans la complexité de l'américanité: une ouverture, une possibilité de cerner les références polymorphes d'une production cinématographique, sans obligatoirement recourir au louvoiement d'un dualisme engoncé où, d'une part, l'américanisation y apparaît comme la quintessence caractérielle d'une société niant l'enchevêtrement du pluralisme culturel à l'échelle continentale qui le nourrit, et où, d'autre part, l'américanité s'y signifie par ondes de choc, comme la trace indélébile d'une pratique fabulatrice s'emmurant dans son propre exotisme...

\section{Université de Montréal}

\section{NOTES}

1 La notion de coproduction sera employée, dans cet essai, dans l'occurrence de sa reconduction «classique» et concernera donc de facto tout film d'allégeance narrative-représentative impliquant nécessairement la participation financière, technique et artistique de plus d'un pays. Ainsi, les ententes de coproduction entre diverses maisons de production et/ou organes de financement (institutionnels ou privés) ne tiennent pas lieu ici de la désignation "coproduction».

2 Il s'agit de l'adaptation cinématographique d'un roman de Jacques Savoie, paru sous le même titre.

3 Film réalisé également à partir d'une adaptation libre de Léa Pool d'un roman d'Yves Navarre, Kurwenal.

4 Allusion faite ici à l'expression employée par Umberto Eco, dans La Guerre du faux (Paris: Grasset \& Fasquelle, 1985), pour traduire l'appétit gargantuesque de l'Amérique - s'entend les Etats-Unis... - pour le «davantage», le «toujours plus», véritable code de référence principiel menant au débordement orgiaque de la saturation du savoir par le visible...

5 En fait, selon Todorov, la connaissance de l'«autre» reposerait essentiellement sur la nécessité du va-et-vient entre soi et l'autre, et non plus seulement sur une attitude principielle favorisant l'immersion de soi dans l'autre, puisque par cette transmutation le soi perd justement le privilège d'être soi. 
6 En ce sens, ajoute Todorov, «(...) on ne peut concevoir une culture qui n'aurait aucune relation avec les autres: l'identité naît de la [prise de conscience de la] différence; de plus, une culture n'évolue que par ses contacts: l'interculturel est constitutif du culturel.»

7 Voir Guy Scarpetta, L'Artifice (Paris: Grasset, 1988).

8 C'est Umberto Eco qui fut l'un des premiers à exposer les bases conceptuelles de l'«oeuvre citationnelle», L'Oeuvre ouverte (Paris: Seuil, 1965); repris par Guy Scarpetta, L'Artifice, op. cit., et plus spécifiquement le chapitre «Du Baroque au cinéma», p. 186-206.

9 Je renvoie principalement à deux ouvrages traitant de la transnationalisation et de la mondialisation de l'audio-visuel: A. Mattelart, X. Delcourt et M. Mattelart, La Culture contre la démocratie? L'Audiovisuel à l'heure transnationale (Paris: Cahiers Libres/La Découverte, 1983); Charles-Albert Michalet, Le Drôle de drame du cinéma mondial: Une industrie culturelle menacée (Paris: La Découverte/Centre fédéral-FEN, 1987).

10 L'atemporalité recoupe, en fait, la notion d'«illusion référentielle», telle que cette dernière peut se présenter dans le discours historique en mal de référent réel... Ainsi, explique Greimas, «il s'agit là d'un jeu de miroirs par lequel le discours historique projette dans le passé une "réalité" présente pour la ramener ensuite de nouveau dans le présent, mais, cette fois-ci, enrichie d'une autorité fondée sur la vérité (...)». A. J. Greimas, «Du discours scientifique en sciences sociales», Sémiotique et sciences sociales (Paris: Seuil, 1978) p. 31.

11 Francis Affergan, Exotisme et Altérité (Paris: P.U.F., 1987).

\section{OUVRAGES CITÉS}

Bedard, Yves et Bellemare, Denis. «Présentation», «Imaginaires du cinêma québécois». Revue Belge du Cinéma 27 (automne 1989).

Robin, Régine. «Notre américanité». Vice-Versa 21 (novembre 1987).

Todorov, Tzvetan. «Le Croisement des cultures». Communications 43. Paris: Seuil, 1986. 